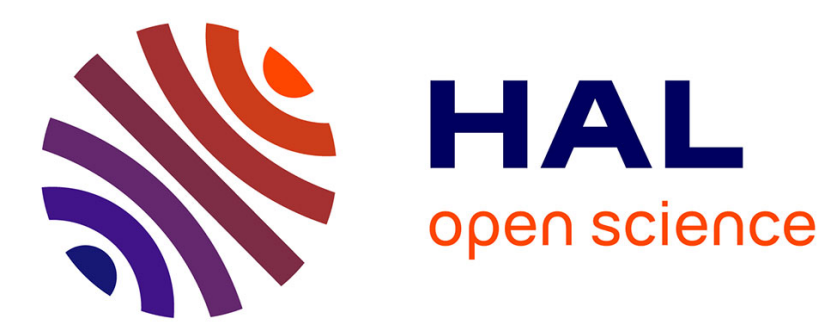

\title{
Persistence in inequalities of frailty at older age: A comparison of nine EU countries
}

Louis Arnault, Florence Jusot, Nicolas Sirven, Marie-Anne Brieu, Didier Halimi, Françoise Forette

\section{- To cite this version:}

Louis Arnault, Florence Jusot, Nicolas Sirven, Marie-Anne Brieu, Didier Halimi, et al.. Persistence in inequalities of frailty at older age: A comparison of nine EU countries. Health and socio-economic status over the life course, De Gruyter Oldenbourg, pp.85-90, 2019, 9783110617245. 10.1515/9783110617245-008 . hal-03457248

\section{HAL Id: hal-03457248 \\ https://hal.science/hal-03457248}

Submitted on 30 Nov 2021

HAL is a multi-disciplinary open access archive for the deposit and dissemination of scientific research documents, whether they are published or not. The documents may come from teaching and research institutions in France or abroad, or from public or private research centers.
L'archive ouverte pluridisciplinaire HAL, est destinée au dépôt et à la diffusion de documents scientifiques de niveau recherche, publiés ou non, émanant des établissements d'enseignement et de recherche français ou étrangers, des laboratoires publics ou privés. 
Louis Arnault, Florence Jusot, Nicolas Sirven, Marie-Anne Brieu, Didier Halimi and Françoise Forette 8 Persistence in inequalities of frailty
at older age: A comparison of nine
EU countries

Women are more at risk of frailty than men.

Strong inequalities exist among men and women according to their levels of education. These social inequalities persisted during 2004-2014.

\subsection{Aim of the study}

Reducing inequalities in health and mortality among socioeconomic groups has become a major goal of health policy in many European countries (Marmot et al., 2008). Although remarkable declines in amenable mortality among groups of both low and highly educated individuals have been achieved, social inequalities in mortality remain large and persistent in Europe and seem to increase among men but remain quite stable among women (Mackenbach et al., 2017).

One way to reduce this gap is to monitor populations that are at risk of over-mortality, with a focus on gender issues, to implement targeted preventive interventions for tackling health inequalities. As such, frailty has become an important indicator to be measured in clinical settings and in the general population (Santos-Eggiman and Sirven, 2016).

Frailty is defined as increased vulnerability to stressors resulting from a decrease in the physiological reserves of multiple systems. Frailty has been operationalized as a phenotype, determined by the presence of a critical number of impairments in physical strength, physical activity, nutrition, mobility and energy (Fried et al., 2001). Studies have shown that frailty is associated with a higher use of healthcare resources and predicts health outcomes, such as occurrence or aggravation of functional limitations, falls, hospitalizations and mortality.

Despite the ever-increasing interest in frailty, little attention has been given to the analysis of social inequality in frailty over time. Analysis of change in the prevalence of frailty over time is particularly relevant because one of the key aspects of the prevention concept is that frailty is reversible. Monitoring changes in 
social inequalities in frailty may be important for designing relevant preventive policies. In addition, although gender issues have always been at the heart of social inequalities analysis, to the best of our knowledge, no study has yet proposed to measure inequalities in frailty by gender from a dynamic perspective. The aim of this paper is to compare the prevalence of frailty by age groups, gender and socioeconomic groups across Europe.

\subsection{Methodology}

We use data from Waves 1, 2, 4, 5 and 6 of SHARE. We consider respondents aged 50+ who answered questions related to frailty, live in the community and reside in countries that participated in the first five standard waves of SHARE (i.e., all but Wave 3, which is retrospective), namely, Austria, France, Germany, Sweden, Denmark, Switzerland, Belgium, Italy and Spain.

Following Santos-Eggimann et al. (2009), who first proposed an operational measures of Fried's frailty phenotype based on SHARE data, we measure frailty as a clinical syndrome in which three or more of the following criteria are observed: shrinking, self-reported exhaustion, weakness as measured by a grip strength lower than several thresholds as defined by gender and BMI groups and slowness as measured by having difficulties walking 100 metres or climbing one flight of stairs without resting and low physical activity. All of these measures were collected from each respondent starting with Wave 1; grip strength is the only non-declarative health measure.

Education is the indicator of the current socioeconomic status that we used to assess social inequality in frailty and more generally to assess social health inequalities. We first develop a binary variable of education based on the International Standard Classification of Education scale (ISCED-97) and consider individuals with a scale equal to 0,1 or 2 as less educated and others as highly educated. Based on this information, we propose assessing the prevalence of frailty by age groups, gender, education groups and waves in Europe. Inequalities in frailty will be analysed by computing the difference in frailty prevalence between less and highly educated groups.

We develop a pseudo-panel approach through which clusters of individuals rather than individuals are the units of analysis. The clusters are groups defined by sex (female, male), age class (50-64, 65-74 and 75+), education levels (low, high), countries (nine European countries) and Waves (1, 2, 4, 5 and 6). These 540 clusters are socio-demographic groups for which the prevalence of frailty is computed at every wave using sampling weights to provide an estimate representative of the population. This method allows a comparison over time through which age 
and year effects can be decomposed: the age effect is given by a comparison of frailty prevalence among age classes at each wave, whereas the year effect is given by the comparison of frailty prevalence among waves for each age class.

Our results depict education-related inequality in frailty prevalence by gender and age group based on a comparison of frailty prevalence (graphs) and time trend (first-difference models with cluster fixed effects). In detail, we provide statistics for:

- Education-related inequalities in frailty prevalence by gender and by age group on the average for all periods (Figure 8.1); and

- Difference-in-difference education-related inequalities in frailty prevalence by gender and age group for all periods (Table 8.1).

\section{Frailty Prevalence in 9 European countries}
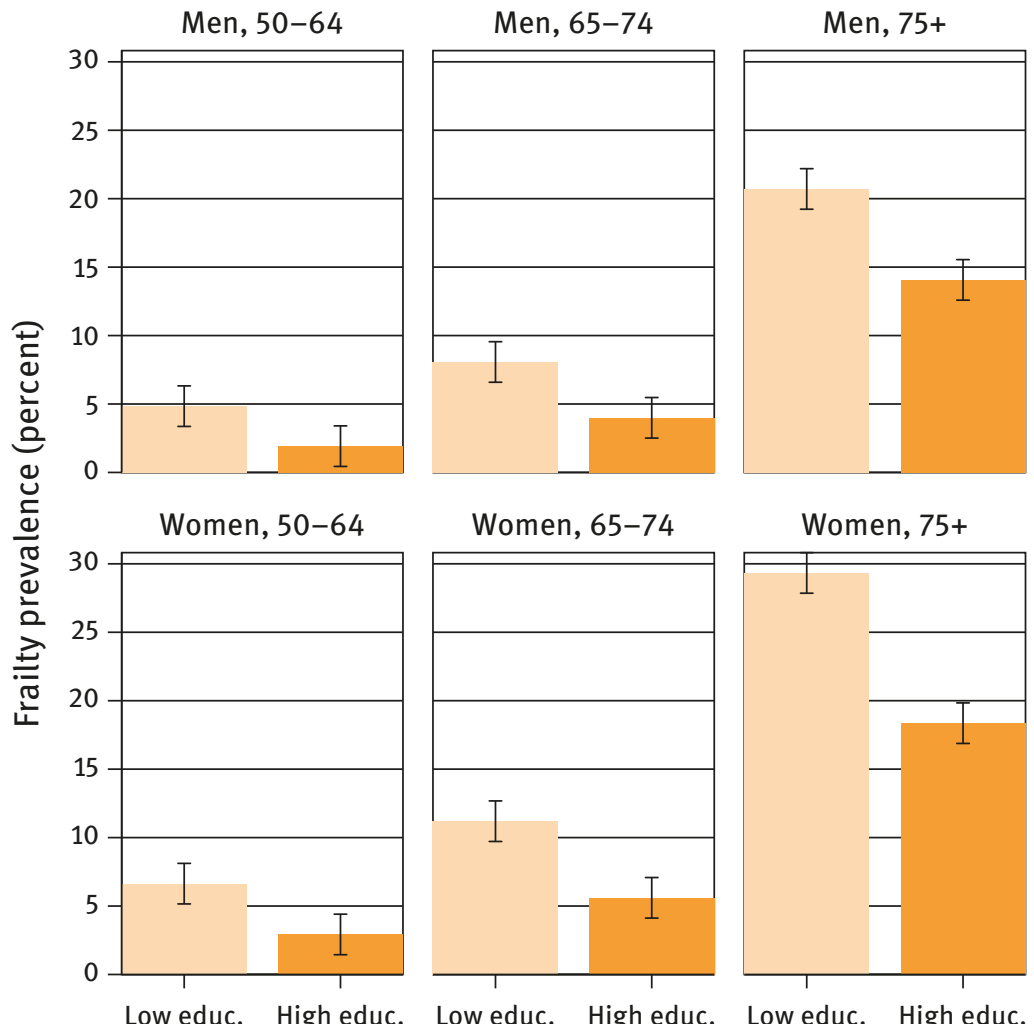

ISCED

Figure 8.1: Frailty Prevalence in 9 European countries.

Source: SHARE Wave 1,2,4,5,6 release 6.1.1. 
Table 8.1: Difference-in-difference of frailty prevalence by education over time in nine European countries.

\begin{tabular}{|c|c|c|c|c|c|}
\hline \multirow{2}{*}{$\frac{\text { Dep. Var. }}{\text { Prevalence of frailty }}$} & \multicolumn{3}{|c|}{ OLS } & \multicolumn{2}{|c|}{ Panel FE } \\
\hline & M1 & M2 & M3 & M4 & M5 \\
\hline \multicolumn{6}{|l|}{ Main variables } \\
\hline Wave $(1,2,4,5,6)$ & 0.01 & 0.01 & 0.01 & 0.01 & 0.01 \\
\hline \multicolumn{6}{|l|}{ Education (ISCED) } \\
\hline Low & ref. & ref. & ref. & - & - \\
\hline High & $-0.05^{\star \star \star}$ & $-0.05^{\star \star \star}$ & $-0.05^{\star \star \star}$ & - & - \\
\hline \multicolumn{6}{|l|}{ Interaction term } \\
\hline Wave x Low educ. & ref. & ref. & ref. & ref. & ref. \\
\hline Wave $x$ High educ. & -0.01 & -0.01 & 0.01 & -0.01 & 0.00 \\
\hline \multicolumn{6}{|l|}{ Controls } \\
\hline \multicolumn{6}{|l|}{ Sex } \\
\hline Men & & ref. & ref. & - & - \\
\hline Women & & $0.03^{\star \star \star}$ & $0.04^{\star \star \star}$ & - & - \\
\hline \multicolumn{6}{|l|}{ Age class } \\
\hline $50-64$ & & ref. & ref. & - & - \\
\hline $65-74$ & & $0.03^{\star \star \star}$ & $0.03^{\star \star \star}$ & - & - \\
\hline $75+$ & & $0.16^{\star \star \star}$ & $0.16^{\star \star *}$ & - & - \\
\hline \multicolumn{6}{|l|}{ Country dummies } \\
\hline (not reported) & & & & - & - \\
\hline \multicolumn{6}{|l|}{ Crossed-terms } \\
\hline \multicolumn{6}{|l|}{ Time invariant } \\
\hline High educ. $x$ Men & & & ref. & - & - \\
\hline High educ. $x$ Women & & & -0.01 & - & - \\
\hline \multicolumn{6}{|l|}{ Time variant } \\
\hline Men x Wave & & & ref. & & ref. \\
\hline Women $x$ Wave & & & 0.01 & & 0.01 \\
\hline High educ. $x$ Men $x$ Wave & & & ref. & & ref. \\
\hline High educ. $x$ Women $x$ Wave & & & -0.01 & & -0.01 \\
\hline Intercept & $0.13^{\star * \star}$ & $0.05^{\star \star \star}$ & $0.05^{\star \star *}$ & $0.10^{\star \star \star}$ & $0.10^{\star \star \star}$ \\
\hline $\mathrm{N}$ & 540 & 540 & 540 & 540 & 540 \\
\hline
\end{tabular}

Note: ${ }^{\star} p<0.1,{ }^{\star \star} p<0.05,{ }^{\star \star \star} p<0.01$.

\subsection{First results}

Our first descriptive results show inequalities in frailty prevalence according to age and gender on average for all periods (Figure 8.1). On average for different periods, the prevalence of frailty is approximately 9 per cent among men and 12 
per cent among women. In addition, regardless of the period considered, we note a strong increase in the risk of frailty with age, at approximately 4 per cent of the population aged 50 to 65,7 per cent of the population aged 65 to 74 and 20 per cent of the population aged 75 and older.

The results of the pseudo panel displayed in Table 8.1 (M1-M3) show that women are always more at risk of frailty than men, and strong social inequalities exist among men and women: the risk of frailty is lower among highly educated individuals. In addition, the risk of frailty increases with age (M2-M3).

Regarding the trends during 2004-2015 (Table 8.1, crossed-terms in M3 and M5), the prevalence of frailty remains quite stable for both women and men. The patterns appear to be similar among education groups, suggesting a persistence of social inequalities in frailty during the period. The time trend is nil (Table 8.1, variable "Wave" in M1-M5), indicating that the prevalence of frailty remained constant over the pseudo-panel. Decomposition of the trend, that is, time-fixed effects crossed with cluster fixed-effects (sex, and education level) one after the other, did not reveal any specific trends between men and women, and similar results occur for education levels. In any case, we find no compensation effect - for instance, when the increase in one cluster is compensated by a decrease in the other cluster such that the average is nil.

\subsection{Conclusion}

This analysis of the trends in inequalities in frailty in Europe from a pseudopanel perspective suggests two main results. First, we account for large and significant social inequalities in the prevalence of frailty between less and highly educated groups: frailty prevalence for less educated men is on average higher by 4.5 percentage points relative to more educated men; this figure increases to 6.7 percentage points for women. These social inequalities tend to increase with age, reaching 6.6 percentage points for men and 10.9 percentage points for women in the 75+ age class. Second, these results are stable over time, meaning that the new generations face a similar risk of frailty as did the previous generation. In a nutshell, social inequalities in frailty are strong and persistent.

Despite many efforts made to date with the aim of reducing social inequalities in health, these inequalities remain large, at least in the case of frailty. Two sets of reasons could be advocated here to explain this result. First, the mechanisms at play may need to be assessed in the long run, such that the period of observation is relatively short. Second, two counteracting effects may 
be at play: medical progress reduces the risk of frailty for any given age but also increases the pool of survivors such that we did not observe any change in the prevalence of frailty over time.

\section{References}

Fried, L. P., Tangen, C. M., Walston, J., Newman, A. B., Hirsch, C., Gottdiener, J., Seeman, T., Willem, R. T., Burke, G., \& McBurnie, M. A. (2001). Frailty in older adults: evidence for a phenotype. The Journals of Gerontology Series A: Biological Sciences and Medical Sciences, 56(3), M146-M157.

Mackenbach J. P. et al., (2017), Determinants of the magnitude of socioeconomic inequalities in mortality: A study of 17 European countries, Health and Place, 47; 44-53.

Marmot, M., Friel, S., Bell, R., Houweling, T., Taylor, S., \& the Commission on Social Determinants of Health (2008). Closing the gap in a generation: health equity through action on the social determinants of health. The Lancet, 372, 1661-1669.

Santos-Eggimann, B., Cuénoud, P., Spagnoli, J., \& Junod, J. (2009). Prevalence of frailty in middle-aged and older community-dwelling Europeans living in 10 countries. The Journals of Gerontology: Series A, 64(6), 675-681.

Santos-Eggimann, B., \& Sirven, N. (2016). Screening for frailty: older populations and older individuals. Public health reviews, 37(1), 7. 